УДК 378.147:811'233'243

DOI: $10.15587 / 2313-8416.2015 .37397$

\title{
ИНДИВИДУАЛИЗАЦИЯ ОБУЧЕНИЯ ИНОСТРАННЫХ СТУДЕНТОВ В КОНТЕКСТЕ КОММУНИКАТИВНО-КОГНИТИВНОГО ПОДХОДА
}

\author{
(С) Е. И. Гейченко, Л. И. Васецкая
}

В статье рассматриваются аспекты индивидуализаџии - фактора эффективности обучения языку иностранных студентов-нефилологов. Принции индивидуализаџии обосновывается как ведущций принщип коммуникативно-когнитивного подхода $к$ обучению иноязычной коммуникации. Предлагаются методчческие модели индивидуализаџии обучения. Описывается соотнесенность свойств обучающихся и приемов обучения. Выделяются признаки индивидуализации и основные компоненты, составляющие стратегию индивидуализации обучения иностранцев

Ключевые слова: принциипы индивидуализаџии, вариативность, открытость учебных программ, стратегии овладения речью, иностранщьы

In this article the aspects of individualization - the factor of effectivity of foreign language studying by students non-philologists are considered. The principle of individualization is grounded as the basic principle of the communicative and cognitive method to studying of the foreign language communications. The methodical models of individualization of studying are suggested. The interrelationship of the qualities of the students and the methods of studying are described. It is shown the main principles of individualization and the main components, which create the strategy of the individualization of the studying of the foreigners

Keywords: principles of individualization, variability, openness of training programs, language acquisition strategies, foreigners

\section{1. Введение}

Языковая подготовка иностранных граждан в вузах нефилологического профиля - достаточно гибкий образовательный процесс, чутко реагирующий на изменения, происходящие в обществе. Существенными признаками такой ситуации является появление новых подходов к обучению, новых технологий, что весьма актуально в настоящее время.

Коммуникативно-когнитивный подход в методике преподавания русского языка как иностранного - также новое направление. Его основная задача вывести иностранного студента на лингвокогнитивный (тезаурусный) уровень усвоения русского языка, активизировав резервные возможности обучаемого.

Язык - это основное средство выражения мысли, получения и передачи знаний, основа всей коммуникативно-когнитивной деятельности. Именно языковые структуры, подлежащие когнитивной обработке в процессе речевой деятельности, по словам С. Е. Григоренко и И. В. Сагалас, считаются определяющими внешний мир в сознании каждой личности.

Важно, что коммуникативно-когнитивное обучение дает возможность иностранцу самому осознавать и учитывать не только структурно-системную, но и коммуникативно-когнитивную значимость изучаемого языкового материала, его использование в речи, что в итоге способствует успешному формированию профессионально-коммуникативной компетенции в целом.

\section{2. Постановка проблемы}

Поскольку при коммуникативно-когнитивном подходе в центре внимания учащийся как субъект обучения, с его опытом, знаниями, интересами, способностями, этно- и психологическими особенностями, постольку принципиально важно строить учебный процесс, в котором интеллектуальная активность обучаемого была максимально высокой.

В основу последнего положен принцип индивидуального подхода, который предполагает учет индивидуальных особенностей студентов и признание того факта, что для каждого иностранца характерен тот или иной способ осуществления деятельности по овладению языком и его применения в процессе общения.

Целью данной статьи является рассмотрение отдельных компонентов индивидуализации обучения, иноязычной речи с позиций коммуникативнокогнитивного подхода.

Индивидуализация требует такой организации учебного процесса, при котором обеспечена мотивация и потребность в осуществлении коммуникативной деятельности, проявление у студента способности пользоваться отрабатываемым языковым материалом в естественных актах общения.

Применительно к обучению иностранному языку выделяют три уровня познавательной активности. Первый уровень - воспроизводящая активность, которая характеризуется стремлением понять новое явление, дополнить и воспроизвести знания, овладеть способом их применения по образцу. Второй - интерпретирующая активность. Ей присуща большая устойчивость волевых усилий, когда учащийся стремится проникнуть в сущность явления, установить связь между языковыми явлениями, самостоятельно находит пути решения при затруднениях. Третий уровень - творческая активность, на данном уровне студенты используют свои знания и умения в новой ситуации, в новых коммуникативных условиях. Отличительной характе- 
ристикой этого уровня считается проявление высоких волевых качеств обучаемых, целеустремленность, упорство и настойчивость в достижении цели, широкие познавательные интересы.

\section{3. Литературный обзор}

В западноевропейской методической литературе чаще всего под индивидуализацией понимается определенная обособленность учебной деятельности студента в виде его индивидуальной работы по индивидуальным программам, предусма-тривающим деление студентов на потоки (группы) по способностям, коммуникативным потребностям. Содержание данных программ отличается объемом и глубиной изучаемого материала, для них характерен принцип вариативности и открытости, который позволяет переход с одного уровня учебной программы на другой более сложный или, наоборот, упрощенный, а также дает возможность аспектного выбора учебного материала.

В последнее время в отечественной методике преподавания иностранных языков проблеме индивидуализации также уделяется много внимания: Арутюнов А. Р., Врублевская Е. С., Николаева С. Ю., Вятютнев М. Н., Демченко В. А., Зимняя И. А., Ковалева Т. М., Кузовлев В. П., Леонтьев А. А., Маслоу А., Протасова Т. Н., Рогова Г. В., Суханова Е. А., Шляхов В. И., Элькони Д. Б. и др. [1-13].

Отметим, что в современной дидактике выделение индивидуального подхода в самостоятельный принцип обучения традиционно и общепризнанно.

В качестве перспективных моделей индивидуализации позитивно зарекомендовали себя методические системы организации учебного процесса иностранных студентов, базирующиеся на индивидуальных планах, накопительной кредитнорейтинговой системе, основанные на технологии модульного обучения, на использовании Интернетресурсов, компьютерных технологий.

С другой стороны, многие исследователи и методисты рассматривают индивидуализацию как организацию учебной деятельности, направленную на формирование коммуникативной компетенции у иностранных студентов посредством уровневой дифференциации содержания обучения, форм и способов его реализации.

В анализируемой методической литературе превалируют единые требования к усвоению содержания учебной программы, а под индивидуализацией обучения чаще всего понимают индивидуальный подход.

Однако понятие «индивидуальный подход» до сих пор трактуется по-разному.

Индивидуализация одними понимается как одна из форм организации учебной работы учащихся на занятии, а не как определенный методический прием подхода к каждому из обучающихся. На наш же взгляд, для обозначения работы с одним учащимся имеется, более точный термин «индивидуальная форма работы».

Другие отождествляют индивидуальный подход с дифференцированным. Но последний - это лишь один из приемов первого, учитывая, что при дифференцированном подходе дифференцируется чаще всего только учебный материал в зависимости от успеваемости того или иного учащегося.

Возразить можно также против такого понимания индивидуального подхода, по которому индивидуализацию считают лишь дополнительной «сверхурочной» работой преподавателя.

4. Теоретическое обоснование принципа индивидуализации как одного из факторов коммуникативно-когнитивного обучения иностранцев

Мы исходим из того, что принцип индивидуального подхода - это принцип активного воздействия на умственное развитие обучающихся, чтобы добиться максимального их развития. Не обучение должно подстраиваться под индивидуальные особенности учащегося, а учащийся должен подстроиться под всё усложняющийся процесс обучения.

Таким образом, индивидуализация обучения есть, по сути, учет всех многосторонних свойств обучающегося и соотнесения с ними приемов обучения. Она пронизывает весь учебный процесс и является одним из условий обучения общению иностранных студентов.

Известно, что на разных стадиях овладения учебным материалом одновременно находятся иностранные студенты с разными коммуникативными потребностями, мотивами изучения языка, возможностями переработки единиц обучения и т. п. Иностранцы с неодинаковой степенью продуктивности выполняют одни и те же предлагаемые операции с единицами обучения. Между тем при фронтально-групповой организации учебного процесса индивидуальные особенности учащихся не учитываются, и поэтому студенты лишаются возможности разрабатывать собственную программу речевого поведения в соответствии с коммуникативными потребностями и на основе наиболее эффективных для них приёмов и способов работы с единицами обучения.

Не исключается, что фронтально-групповая методика обучения может быть применима в определенных условиях. Однако здесь речь идет об индивидуализации обучения для всех, кто при применении одной и той же системы учебных действий сталкивается с многочисленными трудностями, усваивая поступающий материал. Оптимизация учебной деятельности студентов, безусловно, позволит повысить продуктивность обучения и овладения. Ведь качество и скорость овладения языком повышаются по мере того, как техника презентации материала в учебниках будет приближаться к тем комбинациям приёмов и способов, которые применяются иностранными студентами в учебном процессе. Нельзя не согласиться с тем, что в современных учебниках игнорируются индивидуальные особенности овладения языком; предлагается одна и та же техника презентации, тренировки и контроля для всех, одно и то же содержание и его объём. 
Для решения проблемы индивидуализации обучения, как мы полагаем, надо прежде всего выделить все компоненты, составляющие стратегию овладения изучаемым языком. Среди факторов, влияющих на уровень овладения иноязычной речью, необходимо назвать вариативность и открытость учебных программ, которые в настоящее время строятся по модульному принципу.

Вариативность обучающих программ характеризуется многоуровневостью и модификацией учебных планов, их содержания. Принцип вариативности предполагает использование различных технологий, обязывает предоставлять студентам свободу выбора темы для изучения, обеспечивает смену видов речевой деятельности, интенсифицирует включение интерактивных технологий обучения, в том числе, активное использование творческого потенциала иностранного студента.

Индивидуализация и дифференциации обучения позволяют, изменяя структуру, содержание и организацию учебной работы, более полно учитывать уровень языковой подготовки иностранцев, их способности и когнитивный стиль, создавая условия для учебной деятельности в соответствии с их коммуникативными потребностями и мотивационными установками.

Однако все эти основания являются эмпирическими инновациями отдельных методистов, педагогических коллективов и, к сожаленью, не носят системного характера.

Многообразие признаков индивидуализации порождает многообразие моделей обучения, в которых тот или иной признак может быть доминирующим и структурирующим. Но вполне естественно, что практическая реализация этого разнообразия будет ограничена и сдержана реальными условиями осуществления обучения на языковой кафедре - материально-технической базой кафедры, учебно-методическим обеспечением и уровнем профессиональной готовности внедрения инновационных технологий для совершенствования определенного аспекта учебной работы.

6. Практика внедрения принципа индивидуализации на языковой кафедре нефилологического вуза

Предлагаем проанализировать проявление признаков индивидуализации, обращаясь к практике внедрения данного принципа на языковой кафедре ЗГМУ, и обобщить эмпирические представления по данному вопросу.

Еще раз отметим, что принцип индивидуализации предполагает как учет уровня языковой подготовки группы в целом, так и отдельных студентов, требующих помощи в восполнении знаний или в развитии определенных навыков. Этот принцип обязывает создавать разноуровневые курсы для учебной работы студентов одного года обучения. Курсом мы называем аспект языка или речи, подлежащий усвоению и требующий практики применения. Данные курсы реализуются в виде содержательных модулей. Каждый содержа-тельный модуль представляет собой минимальную автономную учебно-методическую единицу определенного содержания, функцио-нирующую в общей системе курса. Например, курс «Практическая грамматика русского языка» (первый год обучения) структурирован на следующие содержательные модули: «Определительные отношения в простом предложении», «Условно-целевые отношения в простом предложении» или, к примеру, курс «Профессиональное общение» (третий год обучения) включает такие содержательные модули, как «Расспрос больных с заболеваниями дыхательной системы», «Диалог-беседа с родителями больного ребенка по заболеваниям сердечно-сусудистой системы» и т. д.

Все содержательные модули делятся на 3 типа: обязательные, вариативные по степени сложности и вариативные по объему.

Обязательный модуль содержит базовый лингвистический, речевой и коммуникативный минимум, необходимый для развития и совер-шенствования требуемого уровня языковой, речевой и коммуникативной компетенций.

В вариативных по степени сложности модулях содержатся варианты заданий, ранжированные по степени трудности. Выбирая из данного множества задания обязательные для каждого отдельно взятого студента, преподаватель тем самым определяет для обучаемых наиболее оптимальный путь овладения необходимыми знаниями и навыками.

В вариативные по объему модули включены задания, количество которых может быть расширено или сокращено в соответствии с уровнем подготовки студентов, в зависимости от их коммуникативных потребностей или других факторов, например, от скорости выполнения задания каждым студентом и т. д. Учет региональных и индивидуально-психологических особенностей иностранных студентов обуславливает дифференциацию в планировании количества учебных тем и заданий. Так, например, эквадорские и индийские студенты по скорости выполнения работы более медлительны, чем студенты из Туниса или Марокко. Поэтому и количественный объем заданий у первых меньше, чем у вторых. Однако это не должно влиять на достижение конечной цели обучения или подменять уменьшение количества заданий их качественным наполнением, т. е. нельзя заменять на задания, облегченные в плане содержательности, целевых установок, заданных речевых действий и т. д.

Бесспорно, на современном этапе проблема индивидуализации обучения неразрывно связана с применением инновационных технологий, среди которых на первом месте Интернет-ресурсы и активное использование компьютерных программ. Подключение обучающих и контролирующих компьютерных программ обеспечивает высокий уровень оптимизации и индивидуализации учебной работы на языковых кафедрах. Работая с этими программами, студенты имеют возможность оперативно реагировать на свои ошибки, исправлять их самостоятельно, имея возможность определять причину своей ошибки посредством вызова на 
монитор компьютера справочного материала по изучаемому аспекту. Компьютерная программа помогает не только в самопроверке, но и в объективном оценивании. И, самое важное, на наш взгляд, студенты получают возможность выбора типа содержательного модуля в пределах обязательного комплекса учебных заданий, заданного преподавателем курса и обозначенного им уровня языковой подготовки.

Безусловно, каждый учащийся, как известно, отличается специфическим стилем приобретения, организации и хранения знаний, умений и навыков для последующего их применения в общении. Степень сочетаемости и интенсивности проявления всех компонентов, составляющих стратегию овладения, объясняют тем, что у каждого учащегося может быть своя стратегия. Эти компоненты вместе с предлагаемой учебником методикой обучения всегда оказывают прямое влияние на образование постоянных, рассчитанных на весь период изучения языка и кратковременных способов овладения.

К числу компонентов, составляющих стратегию овладения, в методике обычно относят такие, как коммуникативные потребности учащихся, способность к языку, мотивация учения, опора на родной язык, склонность к систематизации изученных явлений, соотношение между лёгкостью/ трудностью усвоения и простотой/сложностью учебного материала, самоконтроль, корректировка и др.

Поскольку не все компоненты стратегии овладения в настоящее время достаточно изучены, то, естественно, и учет индивидуальных особенностей обучаемых в учебном процессе осуществляется не в полной мере

Анализ литературы и многолетний опыт преподавания русского языка как иностранного студентам в медицинском вузе позволяет утверждать, что индивидуализации учебного процесса спосо-бствует определение общих методологических и психологопедагогических приоритетов, определение критериев развития познавательной сферы, логико-структурное описание целей и содержания обучения, а также учет субъективных и объективных потребностей обучающихся, их когнитивных и индивидуальных особенностей и способностей.

Как и всякая способность, способность к овладению иностранным языком проявляется в деятельности и представляет собой сочетание разных свойств: способность к усвоению фонетики, лексики, грамматики, к овладению навыками речи (устной и письменной).

К свойствам, которые определяют способность человека к овладению иностранным языком, можно отнести память, определенный уровень процессов мышления, степень развития речевых умений, выработанных на материале родного языка или языка-посредника. Индивидуальные различия обнаруживаются скоростью и прочностью запоминания, точностью и легкостью воспроизведения.

Способность к иностранному языку связана с процессами мышления. Для того, чтобы более успешно осуществлялся процесс обучения, необхо- димо установить, какой тип мыслительной деятельности у того или иного студента. При обучении языку важна не только быстрота умственной ориентировки, но и такие качества мышления, как вдумчивость, творческий подход, систематичность и последовательность. Эти свойства мышления, могущие проявиться только в конкретной деятельности, наиболее характеризуют индивидуальные особенности обучаемых.

Соотношение между упомянутыми способностями к языку у разных учащихся неодинаково. Но эти способности могут развиться при условии, если будет осуществляться дифференцированный подход к учащимся в процессе их обучения.

Следовательно, преподавателям русского языка как иностранного важно учитывать как общие закономерности памяти и мышления, так и индивидуальные особенности обучаемых. А это значит, что добиваясь эффективности учебного процесса по обучению иностранцев русскому языку, необходимо исходить из того, что новый материал или наиболее важная информация должны в разных формах повторяться в течении занятия, иначе она не перейдет в долговременную память.

Иностранным студентам с различными типологическими особенностями памяти полезно давать индивидуальные задания по закреплению нового изучаемого материала и перевода его в долговременную память. И только после усвоения этого материала давать упражнения на развитие других видов памяти.

Каждое занятие должно иметь четкую структуру с делением его на небольшие, но самостоятельные части, что поможет удержать внимание иностранцев на большем количестве материала, т. к. начало и конец получаемой информации возбуждают у студентов наибольшее внимание, а для тех, у кого внимание неустойчивое, полезно давать задания на усвоение материала дозами, порциями, чтобы они, фиксируя свое внимание на начале и конце каждой части, не пропускали нужную информацию.

Важно развивать непроизвольное запоминание у тех студентов, которые используют во всех случаях механическую память, что малопродуктивно для обучения.

Практика преподавания русского языка иностранцам также подтверждает, что процесс выработки речевых навыков и умений у разных студентов требует разного количества упражнений и времени. Отсюда необходимо разрабатывать для каждой типологической группы определенную систему упражнений, которая будет соответствовать индивидуальным особенностям мыслительной деятельности иностранных студентов.

\section{7. Выводы}

Обобщая сказанное, можем констатировать, что учет индивидуальных особенностей студентовнефилологов в процессе изучения ими русского языка как иностранного, без сомнения, способствует 
эффективности их обучения. Целесообразное сочетание различных стратегий индивидуализации в контексте коммуникативно-когнитивного подхода к обучению иноязычной речи позволяет максимально полно реализовать задачи успешного формирования у иностранных студентов коммуникативной и профессиональной компетенций.

\section{Литература}

1. Арутюнов, А. Р. Коммуникативная методика русского языка как иностранного и иностранных языков [Текст] / А. Р. Арутюнов, И. С. Костина. - М., 1992. - 147 с.

2. Гейченко, К. I. Індивідуальний підхід до студентів-іноземців у навчанні мови спілкування [Текст] / К. І. Гейченко, Л. І. Васецька // Актуальні проблеми підготовки фахівців у вищих медичних та фармацевтичному навчальних закладах України. - Чернівці, 2002. - C. 547.

3. Зимняя, И. А. Психология обучения народному языку [Текст] / И. А. Зимняя. - М., 1989. -219 с.

4. Китайгородская, Г. А. Интенсивное обучение иностранным языкам: Теория и практика $[$ Текст] / Г. А. Китайгородская. - М., 1992. -320 с.

5. Леонтьев, А. А. Некоторые проблемы обучения русскому языку как иностранному (психологические очерки) [Текст] / А. А. Леонтьев. - М., 1990. - 189 с.

6. Московская, А. А. Индивидуальная работа со студен-тами на занятиях по иностранному языку [Текст] / А. А. Московская. - Сб. статей по лингвистике и методике преподавания иностранных языков. - М., 1973. - 177 с.

7. Николаева, С. Ю. Индивидуализация обучения иностранным языкам [Текст] / С. Ю. Николаева. - Киев: Вища школа, 1987. - $140 \mathrm{c.}$

8. Протасова, Т. Н. Учет индивидуальных особенностей студентов-иностранцев при обучении чтению на русском языке (начальный этап) [Текст]: автореф. дис. ... канд. пед. наук: 13.00 .02 / Т. Н. Протасова. - МГУ им. Ломоносова. - М., 1973. - 28 с.

9. Труханова, Т. І. Індивідуалізація навчання професійно орієнтованого читання англійською мовою студентів технікумів та коледжів економічного профілю [Текст]: автореф. дис... канд. пед. наук: 13.00.02. / Т. І. Труханова. Киевский национальный лингвистический университет. К.: КНЛУ, 2001. -19 с.

10. Унт, И. Э. Индивидуализация учебных заданий и ее эффективность (на материале 5-8 классов) [Текст] : автореф. дис. ... докт. пед. наук / И. Э. Унт. - Тарту, 1975. $-28 \mathrm{c}$.

11. Шестопалова, I. О. Індивідуалізація навчання іноземних мов у вищий школі Великої Британії [Текст] : монографія / I. О. Шестопалова. - К. : Наук. світ, 2004. $-184 \mathrm{c}$.

12. Шляхов, В. И. Индивидуализация обучения и проблема создания самоучителя русского языка [Текст] : автореф. дис... канд. пед. наук: 13.00.02. / В. И. Шляхов. M., 1982. -19 c.

13. Дифференциация и индивидуализация обучения и воспитания в системе непрерывного образования [Текст] : сб. статей / ред. Е. В. Иванов // Стратегии дифференциации и индивидуализации обучения студентов в русле Болонского процесса и Педагогическое образование: история, современность, перспективы. - Великий Новгород : НГУ им. Ярослава Мудрого, 2012. - 363 с.

\section{References}

1. Arutyunov, A. R., Kostina, I. S. (1992). Komunikativnaya metodika russkogo yazika kak inostranogo. Moscow, 98.

2. Geychenko, K. I., Vasetskaya, L. I. (2002). Individualniy pidhid do studentiv - inozemciv u navchani movi spilkuvannya. Chernivtsy, 547.

3. Zimnyaya, I. A. (1989). Psihologia obucheniya inostrannim yazikam. Moscow, 219.

4. Kitaygorodskaya, G. A. (1992). Intensivnoe obuchenie inostrannim yazikam. Moscow, 320.

5. Leontiev, A. A. (1990). Nekotorie problemi obucheniya russcomu yaziku kak inostranomu. Moscow, 189.

6. Moskovskaya, A. A. (1973) Individualnaya rabota so studentami na zanyatiyah po inostranomu yaziku. Moscow, 177.

7. Nikolayeva, S. Y. (1987). Individualizacia obucheniya inostranim yazikam. Kiev: Vishya Schkola, 140.

8. Protasova, T. H. (1973). Uchet individualnih osobenostey studentov-inostrancev pri obuchenii chteniyu na russkom yazike. Moscow, 28.

9. Truhanova, T. I. (2001). Individualizaciya navchanya profesiino orientovanogo chitanya angliiskoyu movoyu studentiv tehnikumiv ta koledgiv ekonomichnogo profily. Kiev: KNLU, 19.

10. Unt, I. E. (1975). Individualizaciya uchebnih zadaniy i efektivnost (na material 5 - 8 klassov. Tartu, 28.

11. Shestopalova, I. O. (2004). Individualizaciya navchannya inozemnih mov u vishuy schkoli Velikoyi Britaniyi. Kiev: Naukoviy svit, 184.

12. Shlyahov, V. I. (1982). Individualizaciya obucheniya i problema sozdaniya samouchitelya russkogo yazika. Moscow, 19.

13. Smith, E. C. (Ed.) (2012). Differnciacia i individualizaciya obucheniya $\mathrm{i}$ vospitaniya $\mathrm{v}$ sisteme neprerivnogo obrazovaniya: Sb. Statey Megdunarodnoy nauchno - prakt. konf. Velikiy Novgorod, 363.

Рекомендовано до публікаиії д-р пед. наук, професором Іваненко В. К. Дата надходження рукопису 25.01.2015

Гейченко Екатерина Ивановна, заведующий кафедрой, кафедра языковой подготовки, доцент, Запорожский государственный медицинский университет, пр. Маяковского, 35, г. Запорожье, Украина, 69035

Васецкая Лариса Ивановна, доцент, кафедра языковой подготовки, доцент, Запорожский государственный медицинский университет, пр. Маяковского, 35, г. Запорожье, Украина, 69035 E-mail: larysa_v@mail.ru 